\title{
Design and development of a cross-cultural disposition inventory
}

\author{
Randall Davies \\ Brigham Young University - Provo, randy.davies@byu.edu \\ Holt Zaugg \\ Brigham Young University - Provo, holt_zaugg@byu.edu \\ Isaku Tateishi \\ Brigham Young University - Provo, isaku80@gmail.com
}

Follow this and additional works at: https://scholarsarchive.byu.edu/facpub

Part of the Educational Psychology Commons

\section{Original Publication Citation}

Randall Davies, Holt Zaugg \& Isaku Tateishi (2014): Design and development of a cross-cultural disposition inventory, European Journal of Engineering Education, http://dx.doi.org/10.1080/ 03043797.2014.915289

\section{BYU ScholarsArchive Citation}

Davies, Randall; Zaugg, Holt; and Tateishi, Isaku, "Design and development of a cross-cultural disposition inventory" (2014). Faculty Publications. 1454.

https://scholarsarchive.byu.edu/facpub/1454

This Peer-Reviewed Article is brought to you for free and open access by BYU ScholarsArchive. It has been accepted for inclusion in Faculty Publications by an authorized administrator of BYU ScholarsArchive. For more information, please contact ellen_amatangelo@byu.edu. 


\title{
The Design and Development of a Cross-Cultural Disposition Inventory
}

\begin{abstract}
Advances in technology have increased the likelihood that engineers will have to work in a global, culturally diverse setting. Many schools of engineering are currently revising their curricula to help students develop cultural competence. However, our ability to measure cultural dispositions can be a challenge. The purpose of this project was to develop and test an instrument that measures the various aspects of cultural disposition. The results of the validation process verified that the hypothesized model adequately represented the data. The refined instrument produced a four factor model for the overall construct. The validation process for the instrument verified the existence of specific subcomponents that form the overall cultural disposition construct. There also seems to be a hierarchical relationship within the subcomponents of cultural disposition. Additional research is needed to explore which aspects of cultural disposition affect an individual's ability to work effectively on a culturally diverse engineering team.
\end{abstract}

Keywords: cross-cultural competencies; cross-cultural education; global engineering

Citation:

Davies, R., Zaugg, H., \& Tateishi, I., (accepted April 2014). The Design and Development of a Cross-Cultural Disposition Inventory. European Journal of Engineering Education, xx(x), xx-xx.

Authors Contact:

RANDALL DAVIES, ISAKU TATEISHI

Instructional Psychology \& Technology, Brigham Young University, 150 MCKB, Provo, UT, 84602, USA

E-mail: randy.davies@byu.edu, isaku80@gmail.com

HOLT ZAUGG

Educational Measurement Inquiry and Evaluation, Brigham Young University, 150 MCKB, Provo, UT, 84602, USA

E-mail: zaugg@gmail.com 


\section{Introduction}

Increases in international commerce and the importance of foreign markets have necessitated global collaboration including culturally diverse groups of people (Ferraro, 2006). Certainly many countries have become more ethnically and culturally diverse from within (Friesen and Ingram, 2013). In addition, advances in communication technology have increased the likelihood that individuals will need to work in culturally diverse settings, and have even changed the nature of teams and the skills needed to be effective team members (Prasad \& Akhilesh, 2002). As a result, research related to engineering education has gone global (Jesiek, Borrego \& Beddoes, 2010). The importance of training engineering students with the skills and attitudes they will need to work effectively in the global work place has prompted many schools of engineering to modify their curriculum (Duderstadt, 2008; Wojciechowski \& Standridge, 2010). Three major challenges have developed: 1) defining the set of global competencies engineering students will need; 2) determining the best way to help students develop crosscultural competence; and, 3) measuring the degree to which students possess the requisite skills and dispositions that have been identified as important (Deardoff, 2011; Fantini, 2009; Lohmann, Rollins \& Hoey, 2006). Much research has been conducted in the area of defining global engineering skills and dispositions (Ball et al., 2011; Deardoff, 2011; Hunter, White \& Godbey, 2006; Jansen \& Pudlowski, 2009; Parkinson, 2009; Spitberg \& Changnon, 2009). Many schools of engineering are currently developing curricula to help students develop cross-cultural competence. However, our ability to measure aspects of global competence among engineering students is still at a formative stage (Grudzinski, Jellison, Stewart-Gambino, \& Weisman,2007).

The term global competence represents a conglomeration of knowledge, abilities, and dispositions related to challenges individuals will encounter when working on culturally diverse teams. One's ability to work effectively in a global team setting often depends on knowing and understanding how people from different parts of the world communicate, what they value, and how they perceive various aspects of the world politically, socially, and economically (Ferraro, 2006; Barczak, McDonough \& Athanassiou, 2006; Brandl \& Neyer, 2009; McNair, Paretti \& Kakar, 2008; Rasmussen \& Wangel, 2006; Spitberg \& Changnon, 2009). This type of knowledge and

understanding is cognitive: It can be taught and tested in classrooms using traditional assessment methods including performance assessments. However, cultural competence also involves an affective component. Attitudes or 
dispositions fall into the affective domain of learning outcomes, which are taught and measured quite differently from cognitive knowledge and understanding (Anderson \& Bourke, 2000; Miller, Linn \& Gronlund, 2009).

There have been several instruments developed to measure intercultural competence. Many of the existing instruments attempt to measure cultural competencies by testing knowledge and understanding (i.e, cognitive competence) along with some affective constructs (see for examples Olson \& Kroeger, 2001; Ruben \& Kealey, 1979; Sinicrope, Norris \& Watanabe, 2007; Koester \& Olebe, 1988). The majority of these focus on intercultural communications and awareness (Fantini, 2009; Spitberg \& Changnon, 2009). Other instruments focus on a particular aspect of cultural competence like ethoncentricism-the belief that one's own culture is superior to others (Neuliep \& McCroskey,1997). However, cognitive (knowledge, understanding and ability) should be tested separately from attitudes and beliefs for two reasons: 1) Many participants have a discrepancy between what they feel or believe about their global competence and their actual abilities and actions (Olson \& Kroeger, 2001; Alshuler, Sussman, \& Kachur, 2003), and 2) different types of instruments are used to assess these constructs (Anderson \& Bourke, 2000). As one's disposition toward culture is a complex construct influenced by several integrated aspects of personality, experience, and context, creating an instrument to measure dispositions is challenging.

This research was part of a larger NSF study that initially examined what competencies should be taught and how one might best teach cultural competence to engineering students. While there is considerable disagreement on what constitutes intercultural competence (Deardoff, 2011), this research builds on the work of Ball et al. (2011), which synthesized the literature on global competencies and established a list of five general categories experts in the field felt engineering students need to possess in order to be productive in the global work place. One of the categories identified was cross-cultural dispositions. The purpose of this project was to develop and test an instrument that specifically measures the various aspects of cultural disposition. It was believed that an instrument like this might be used either to measure changes in disposition, resulting from some instructional intervention, or as an instructional tool to help students reflect on their attitudes and belief since this type of activity is one of the first steps in developing affective characteristics (Miller, Linn \& Gronlund, 2009).

\section{Background Information}

Ball et al. [2011] conducted a review of research literature related to international education for engineering students. The purpose of their efforts was to identify a definitive list of global competencies experts felt were 
necessary for engineering students to successfully work in a global, culturally diverse work environment. The resulting compilation of global competencies identified five general topics or categories important to the global competence of engineering students: 1) cross-cultural communication, 2) cross-cultural dispositions, 3) world knowledge, 4) cross-cultural team skills, and 5) engineering specific cross-cultural competencies. Of these topics, cross-cultural disposition is different from the others, as it is the only one that falls within the affective domain of educational outcomes. Each of the others can be learned through direct instruction and practice, but dispositions must be developed over time, and there is no one easy way to directly measure the outcome.

\subsection{Cross-cultural Dispositions Defined}

Cross-cultural dispositions fall within the affective domain. These cultural attitudes are made up of several subcomponents or aspects (see Table 1), which, taken as a whole, make up or determine one's cultural disposition (Ball et al., 2011).

\section{Table1}

Theoretical Subcomponents of Cultural Dispositions

Cultural Appreciation: Appreciates and respects cultural differences (e.g., differences in language, social rules, political systems, arts, music, etc.)

Cultural Openness: Recognizes cultural differences from a perspective different from one's own cultural norms

Cultural Flexibility: Tolerates and flexibly deals with cultural differences without being emotionally distressed

Global Exploration: Desires to learn about different cultures, events, and social issues of the world

Cultural Equality: Views all cultures without prejudice, stereotypes, and discrimination, interacting with people from any culture as equals in social status

Global Citizenship: Desires to help or work with people from different countries to solve cross-cultural or global problems 


\subsection{The Affective Domain}

In 1956 Bloom first identified a taxonomy of educational objectives for the cognitive domain. He later suggested that an additional taxonomy was needed for the affective domain (Krathwohl, Bloom \& Masia, 1973). While the cognitive domain involves remembering, understanding, and performing high-level cognitive tasks (e.g., analysis or critical thinking), the affective domain covers attitudes and beliefs that involve feelings and opinions. Attitudes (or dispositions) are believed to be important affective outcomes because they often determine how people behave and provide a foundation for their motivation to act (Anderson \& Bourke, 2000). The five major categories of the affective domain are listed in Table 2 from the simplest affective behavior or activity to the most complex.

They represent a hierarchical approach by which educators might understand and help students develop specific desirable affective outcomes. Anderson and Bourke (2000)] point out that values and attitudes will be learned whether or not they are intentionally taught. When affective educational outcomes are deliberately promoted, they can only be developed, and often change, over an extended period of time through a hierarchical process of development.

\section{Table 2}

Bloom's Taxonomy for the Affective Domain

Receiving: Being aware and willing to listen to ideas or beliefs different from those held by the individual

Responding: Asking questions about new ideas, concepts, models, or values in order to fully understand them

Valuing: Accepting that others may hold values or beliefs different to one's own; tolerating and being sensitive towards individual and cultural differences

Organizing: Prioritizing by contrasting different values, resolving conflicts between them; placing emphasis on comparing, relating, and synthesizing values

Forming a value complex: Internalizing specific values so that the adopted value system dictates a consistent predictable pattern of behavior

\subsection{Development and Measurement of Dispositions}

Promoting an intended outcome in the affective domain requires educators to utilize a different set of instructional activities and strategies from those used for cognitive outcomes. For students to develop a certain disposition they must be taught the relevant concepts and ideas but then be allowed to form the desired attitude on their own. Students must be given the opportunity to experience a variety of situations in which they will be 
exposed to the various aspects of the construct. Ideally, through this process they will reflect and compare their personal attitudes as they begin refining and shaping the desired affective dispositions.

Measuring affective outcomes is different from the type of testing appropriate for learning outcomes in the cognitive domain. The various aspects of the construct must be conceptually and operationally defined (Anderson \& Bourke, 2000). Then an attitudinal scale must be created. Because these characteristics cannot be measured directly, self-report instruments are typically the most effective way to measure affective outcomes. Development of such an instrument will be the main topic of this paper.

\section{Methods}

\subsection{Setting and Participants}

This project was initiated as part of a larger NSF grant studying the development of cultural competencies for engineering students. The instrument described in this study, the Cross-cultural Disposition Inventory (CDI), was targeted for engineering students working within global virtual teams (GVTs) or participating in a study abroad experience. Participants for the validation process is describe in section 3.2. Participants used to test the instrument are described in section 3.3. The goal of this project was to establish and test an instrument that could be used to measure the cultural dispositions of these engineering students.

\subsection{Instrument Creation and Validation}

Based on the set of dispositional components identified by Ball et al. (2011), a domain-reference approach (see Anderson \& Bourke, 2000) was used to create potential items for the CDI. This approach to item writing begins with a critical examination of the critical features of the construct. Item creation first focuses on the target and direction of a response, then the intensity of response toward the affective characteristic being considered.

The initial instrument included 29 items, with 4 to 7 items for each of the five subcomponents of the scale. Items were created and refined by the research group to align with the various constructs. A general rule for validating an instrument is to make sure the sample size is at least 10 times the number of items (Anderson $\&$ Bourke, 2000). In total, 468 undergraduate students responded, more than enough to validate the instrument. Because of institutional review board restrictions, we could not randomly sample but were required to solicit participants using an open invitation protocol. To get a more representative sample for the validation process and to maximize the variation for the analysis, undergraduate students from the fields of both engineering and education 
were recruited by going into classes and, with the instructors' permission, asking students to complete the CDI voluntarily. The goal was not only to get a sufficient number of responses but also to have a diverse representation of attitudes, gender, beliefs, and experience. The degree to which this was accomplish could not be ascertained as all respondents participated anonymously according to institutional review board approval requirements.

The validation process involved two phases: a principal component analysis (PCA) and a confirmatory factor analysis (CFA). The PCA analyses item clusters statistically to identify correlated groups of items. The PCA was run to determine whether the items we created for this instrument adequately measured the five original constructs and whether these principal components might serve as indicators of an individual's cultural disposition. Based on this analysis the item set was reduced to those items that seemed to best reflect the constructs of interest. From the refined set of items, the second phase of the validation process used a CFA to verify the distinctiveness of the subconstructs measured by the instrument. This process was used to further refine the set of items used to measure each of the constructs. Cronbach's Alpha was also calculated as an indication of internal consistency for the resulting instrument. Students participating in this part of the study who were completing a study abroad experiences all came from the same engineering program. Students involved in a GVT experience were all invited to participate and came from eight universities in diverse location around the world.

\subsection{Testing the Instrument}

Once the instrument was validated, it was tested on groups of engineering students participating in either a global virtual team (GVT) or study abroad situation. The GVT participants used to test the instrument included 52 mechanical engineering students (18 from North American and 32 international students; of which 7 were female and 45 were male students) representing the countries of Canada, China, Brazil, Korea, Mexico, Taiwan and the United States. Each of these students participated in an engineering design course (synchronously or asynchronously) at their respective universities. As part of the course each of the student worked on a GVT to complete a design project. In addition, the testing phase included 97 study abroad students (11 female and 86 male students). These individuals, from one college of engineering in the US, participated in a variety of study abroad experiences outside the US working in diverse cultural settings on engineering related projects. The students for both groups had completed two or more years of undergraduate studies in engineering. Students were tested prior to and after their experience. A total of 129 students ( 83 study abroad and 46 GVT students) completed both the pretest and posttest administrations of the CDI. 
CDI results were compared using a 2x2 repeated measures factorial ANOVA to explore any significant changes within and between groups, allowing us to compare differences over time as well as by instructional experience. An ANOVA and descriptive statistics were also used to explore differences in the overall and disaggregated sub-score results. We pilot tested the instruments to determine whether the CDI might be used to determine any changes in disposition that might have resulted from students participating in a team-based experience involving a globally diverse set of participants.

\section{Results}

\subsection{Items for the Original CDI}

As prescribed by Anderson and Bourke (2000), the initial items created for this instrument were developed using a domain reference approach (see Table 4). The constructs of openness and flexibility were collapsed into one component because items created for these two constructs tended to be very similar. To be culturally flexible (i.e., to tolerate and to compromise) would require an individual to be culturally open (i.e., to understand and be aware of cultural differences). Based on an analysis of the results the designers felt that the items developed for these two components were too similar to differentiate between the subconstructs. The resulting instrument included five dispositional constructs with 4 to 7 items in each construct. The response scale used for the instrument utlilized a fully anchored Likert scale (see Table 3), asking the respondants to indicate the degree to which each of the statements was true about themselves. Negatively worded items had to be reverse scored.

Table 3

Response scale used for the CDI instrument

\begin{tabular}{l}
\hline Response options \\
\hline 1- Almost never true \\
2- Sometimes true \\
3- Usually true \\
4. Frequently true \\
5. Almost always true \\
\hline
\end{tabular}


Table 4

Initial Items for the CDI Scale Presented by Dispositional Component

Cross-cultural appreciation

1 I love to watch foreign films.

2 I like to learn about foreign cultures.

3 I like to try new ethnic food.

$4 \quad$ I like to listen to a variety of ethnic cultural music.

5 Learning about world events is important to me.

Cross-cultural openness/flexibility

6 Learning about foreign cultural practices builds a better community.

7 I respect ideas and beliefs of people from foreign cultures.

8 It is important to communicate with people in their native language.

$9 \quad$ I adapt my actions when working with other cultures.

Cross-cultural equality

10 I do better when my managers and supervisors are from my own country and cultural background.

11 Incorporating foreign cultural practices is beneficial to our society.

12 I DO NOT feel comfortable being examined by a doctor who speaks with a foreign accent.

13 Community and government are stronger with diversity of ethnic representation.

14 I feel more comfortable living in a neighborhood with similar ethnic backgrounds to my own.

15 Minority groups within a country should conform to the customs and values of the majority.

Global exploration

16 Working and living in a foreign country is something that I would really like to do.

17 I take opportunities to learn about other cultures.

18 I read or watch world news.

19 I love spending time with people from other cultures.

20 I love learning new languages.

21 I have close friends from different cultures.

22 I would accept a job offer to work and live in another country.

Global citizenship

23 I have a strong desire to help struggling countries in the world.

24 I donate money for or participate in international humanitarian causes.

25 Taxes in this country should NOT be used for international aid.

26 Our country should welcome refugees and immigrants.

27 Government should make policy to make a positive global impact.

28 Local government needs to take care of its own interests.

29 I think a lot about the influence that society has on other cultures. 


\subsection{PCA Result and Revisions}

An initial step in the validation process utilized a principal component analysis (PCA) with a varimax rotation. We ran the PCA on our data to determine 1) whether the items we created for this instrument adequately measured the five original constructs identified and 2) how well items functioned together in indicating students' attitudes toward global diversity. After we had run the analysis, items that had loading values of less than .300 were eliminated. Other items were removed that did not correlate well with any specific group of items (i.e., Eigen values for the component were less than 1). Cross-loaded items were reviewed to make sure that there was a logical reason for the cross loading and to determine which items should be included in each of the subconstruct categories. A total of 10 items were removed, leaving 19 items in the inventory. This result produced five principal components as intended (each with Eigen values greater than 1). The internal consistency of the instrument, as measured by a Cronbach's alpha calculation using the remaining items only, was .816 , indicating the items tended to function well together in measuring the overall construct. Table 5 presents the results of the PCA analysis. Constructs are organized by items which load most closely with that construct. Cross loaded items (i.e., those that appear in two construct columns) contribute to more than one construct.

\subsection{CFA Results and Revisions}

A second step in the validation process was to run a confirmatory factor analysis (CFA) on the remaining data using SPSS's Amos structured equation modeling statistical software. The resulting model, using standardized estimates, seems to provide an adequate representation of the construct under investigation (see Figure 1). The factor loading estimates for items and constructs are represented. Items that had loading values of less than .300 were eliminated as a candidate for that factor. On According to Byrne (2010), a comparative fit index (CFI) statistic, which takes into account the complete covariance in the data, between .90 and 1.0 is very good; our CFI was .819. Byrne (2010) further suggested that a root mean squared error of approximation (RMSEA) statistic less than .05 indicates an excellent fit; our RMSEA was .047. These results indicate that the hypothesized model adequately represented the data. The results of this analysis produced a four factor model for the overall construct of cultural disposition, as items intended to measure the construct of cultural appreciation were combined with items for cultural openness and flexibility in order to obtain an adequate model representing the intended overall construct of cultural disposition. Based on the results of the CFA, the number of items on the CDI was reduced to 15 items with four underlying subconstructs (see Table 6). The internal consistency of the final 15-item instrument, as measured 
by a Cronbach's alpha calculation, was .700, indicating the items tended to fit fairly well together in measuring the overall construct. The analysis in Figure 1 estimates of association between factors were all greater than .80. This indicates that there is some degree of relationship between these factors which likely contributes to the overall disposition we have attempted to measure.

Table 5

PCA Results for Initial Set of Items

\begin{tabular}{|c|c|c|c|c|c|}
\hline Item \# & 1 & 2 & 3 & 4 & 5 \\
\hline I take opportunities to learn about other cultures. & .726 & & & & \\
\hline I adapt my actions when working with other cultures. & .629 & & & & \\
\hline I like to learn about foreign cultures. & .579 & & & & \\
\hline I love learning new languages. & .564 & & & & \\
\hline I have close friends from different cultures. & .504 & & .435 & & \\
\hline I think a lot about the influence that society has on other cultures. & .465 & .410 & & & \\
\hline I love spending time with people from other cultures. & .358 & & .358 & .487 & \\
\hline $\begin{array}{l}\text { Community and government are stronger with diversity of ethnic } \\
\text { representation. }\end{array}$ & & .669 & & & \\
\hline Government should make policy to make a positive global impact. & & .660 & & & \\
\hline Leaning about foreign cultural practices builds a better community. & & .624 & & .382 & \\
\hline Incorporating foreign cultural practices is beneficial to our society. & & .546 & & & \\
\hline $\begin{array}{l}\text { I donate money for or participate in international humanitarian } \\
\text { causes. }\end{array}$ & & .457 & & & .380 \\
\hline Our country should welcome refugees and immigrants. & & .445 & & & \\
\hline $\begin{array}{l}\text { I feel more comfortable living in a neighborhood with similar } \\
\text { ethnic backgrounds to my own. }\end{array}$ & & & .803 & & \\
\hline $\begin{array}{l}\text { I do better when my manager and supervisor are from my own } \\
\text { country and cultural background. }\end{array}$ & & & .780 & & \\
\hline $\begin{array}{l}\text { Minority groups within a country should conform to the customs } \\
\text { and values of the majority. }\end{array}$ & & & .489 & & \\
\hline I read or watch world news. & & & & & .834 \\
\hline Learning about world events is important to me. & & & & & .751 \\
\hline I respect ideas and beliefs of people from foreign cultures. & & & & .752 & \\
\hline
\end{tabular}




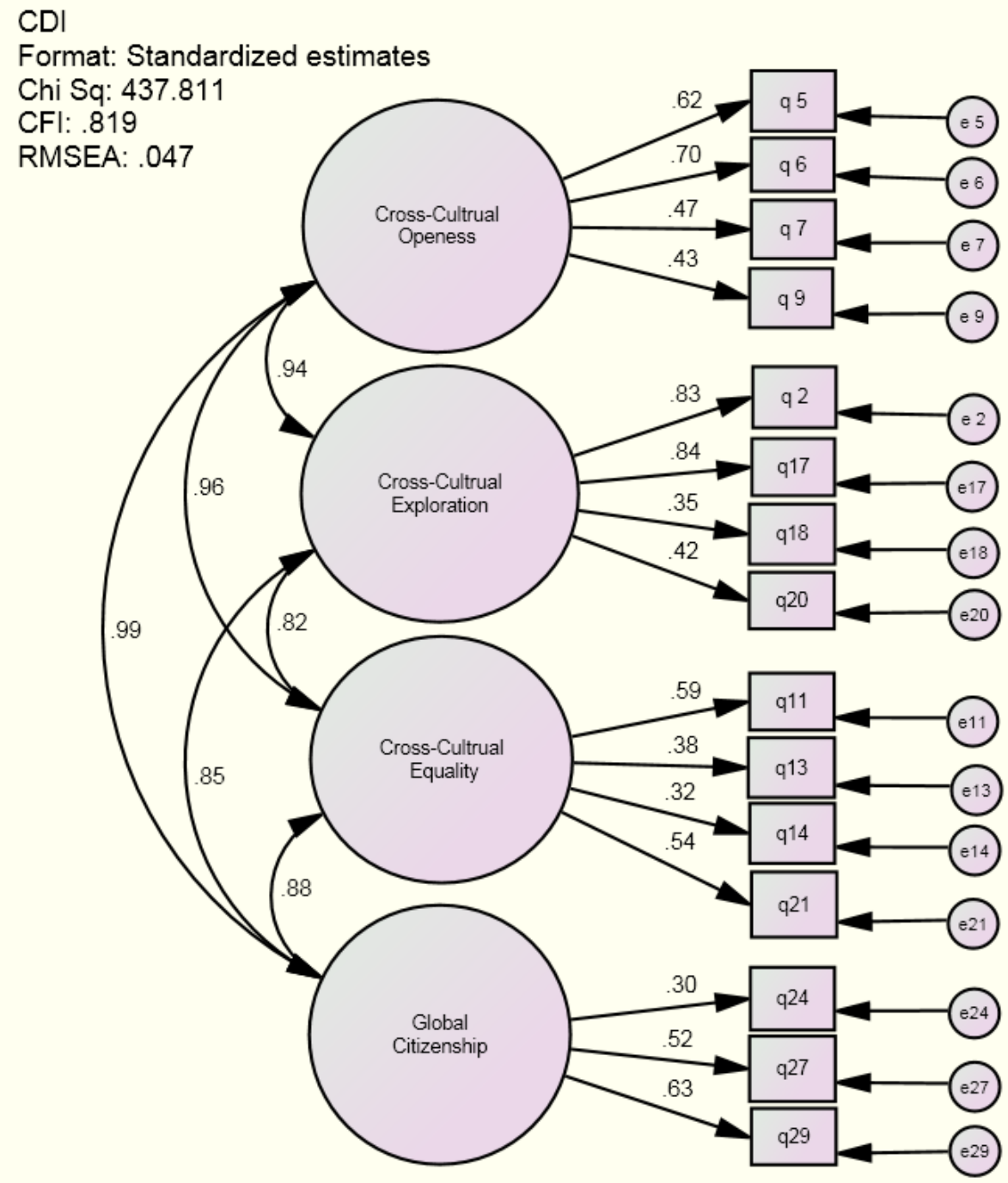

Figure 1. CFA results verifying four distinct sub-constructs that form a part of the larger overall construct of cross-cultural competence

\subsection{Descriptive Analysis of Finalized CDI Instrument}

The total CDI score possible was 75 . The mean CDI score obtained from the validation group was 55 (with a SD of 7.6). Because the subscale construct global citizenship had fewer items than the other subscale constructs, average subscale scores were converted to a common standardized metric (i.e., out of 5) for ease of comparison. Table 7 presents the results. Figure 2 presents the freqency distribution for the standardized CDI scores. The shape of the distribution suggests that cultural dispositions are normally distributed in this population. 
Subscales of the CDI were compared using an ANOVA to determine whether individual components of cultural disposition varied within the overall construct. The result shows a statistically significantly difference when each of the components is compared with the others, $F(3,1868)=110.7, \mathrm{p}<.001$. The average scores of individual subscales seem to indicate there may be a somewhat hierarchical pattern to the various aspects of cultural dispositions. This pattern is explored again later in the analysis.

Table 6

Remaining CDI Scale Items after Revisions based on CFA Results

Cross-cultural openness/flexibility

q5 Learning about world events is important to me.

q6 Learning about foreign cultural practices builds a better community.

q7 I respect ideas and beliefs of people from foreign cultures.

q9 I adapt my actions when working with other cultures.

Global exploration

q2 I like to learn about foreign cultures.

q17 I take opportunities to learn about other cultures.

q18 I read or watch world news.

q20 I love learning new languages.

Cross-cultural equality

q11 Incorporating foreign cultural practices is beneficial to our society.

q13 Community and government are stronger with diversity of ethnic representation.

q14 I feel more comfortable living in a neighborhood with similar ethnic backgrounds to my own.

q21 I have close friends from different cultures.

Global citizenship

q24 I donate money for or participate in international humanitarian causes.

q27 Government should make policy to make a positive global impact.

q29 I think a lot about the influence that society has on other cultures. 
Table 7

CDI results for validation group disaggregated by scaled sub-scores

\begin{tabular}{lcc}
\hline Scale & Mean $^{*}$ & SD \\
\hline Overall CDI (out of 75) & 55.0 & 7.60 \\
Overall CDI (standardized out of 5) & 3.7 & 0.51 \\
Cross-cultural openness/flexibility & 4.0 & 0.57 \\
Global exploration & 3.5 & 0.64 \\
Cross-cultural equality & 3.7 & 0.73 \\
$\quad$ Global citizenship & 3.3 & 0.79 \\
\hline
\end{tabular}

${ }^{*} \mathrm{n}=468$

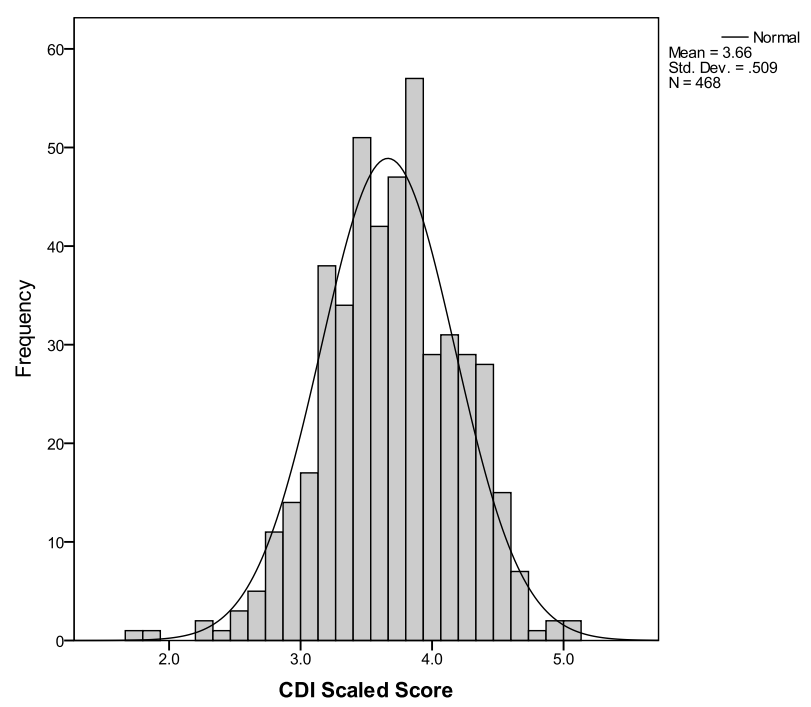

Figure 2. Response distribution for score on the validated CDI using standardized scores. The resulting shape suggests that cultural dispositions are somewhat normally distributed in this population. 


\subsection{Pilot Test results}

The finalized CDI instrument was additionally tested by administering pretest and posttest assessments to undergraduate engineering students participating in either a GVT or study abroad experience. A total of 149 students were asked to complete pretest and posttest administrations of the CDI (97 study abroad and 52 GVT students). Of these, $87 \%$ (129) of the respondents completed both the pretest and posttest administrations (83 study abroad and 46 GVT students). Because personality traits like cultural disposition are believed to be fairly stable, we expected that average changes in disposition would not be extreme. We recognize that attitudes do change, but that they change gradually based on the type of experience an individual encounters (e.g., positive or negative, extreme or mild), as well as the amount and quality of self-reflection the individual undertakes.

The CDI pilot test results were compared using a 2x2 repeated measures factorial ANOVA to explore any significant changes within and between groups. We examined effects of time (pretest to posttest) and experience type (study abroad vs. GVT). The analysis showed a significant difference for the main effect of time but not for the type of experience. Overall the students reported a statistically significant increase in their cultural disposition of approximately 2 points on average, $F(1,127)=8.75, \mathrm{p}=.004$. The GVT students' and the study abroad students' average scores varied similarly over time, $F(1,127)=.085, \mathrm{p}=.771$, with both groups demonstrating a similar pattern of change (i.e., no significant differences between the two groups in the magnitude of reported change: $F(1$, $127)=.003, \mathrm{p}=.957)$. Table 8 presents the descriptive statistics for this analysis. An analysis of the descriptive statistics regarding the direction of the reported changes indicates that, while most students felt their attitudes regarding culture had improved $(53 \%)$, about one third of the students reported a negative change in their cultural disposition (see Table 9).

An analysis of the subscale results closely mirrors the results from the validation group. An ANOVA showed that average scores were similar for pilot test group and the validation group. This result also seems to indicate a pattern in the subcomponents of the overall cultural disposition construct. Participants tended to score highest on the openness/flexibility aspects of cultural competence, indicating that they were more likely to be willing to explore other cultures than they were to believe in cross-cultural equality. They were least likely to indicate a positive attitude toward global citizenship. This pattern seems to imply a natural hierarchical relationship in the subcomponent of cultural competence. 
Table 8

CDI results for pilot test group disaggregated by group and scaled sub-scores

\begin{tabular}{lcccc}
\hline Scale & Pretest Mean & SD & $\begin{array}{c}\text { Posttest } \\
\text { Mean }\end{array}$ & SD \\
\hline Overall CDI (out of 75) ${ }^{*}$ & 53.2 & 8.5 & 55.2 & 9.4 \\
Study Abroad experience $(\mathrm{n}=83)$ & 53.2 & 8.3 & 55.2 & 9.4 \\
GVT experience (n=46) & 53.3 & 9.0 & 54.9 & 8.0 \\
Overall CDI (standardized out of 5) & 3.5 & 0.6 & 3.7 & 0.6 \\
Cross-cultural openness/flexibility & 4.0 & 0.6 & 4.1 & 0.6 \\
Global exploration & 3.6 & 0.8 & 3.8 & 0.8 \\
Cross-cultural equality & 3.4 & 0.7 & 3.4 & 0.7 \\
Global citizenship & 3.1 & 0.8 & 3.3 & 0.9 \\
\hline$*$
\end{tabular}

Table 9

Study Abroad and Global Virtual Team compared by positive negative change in CDI pre to post

\begin{tabular}{lcccc}
\hline Experience & $\mathrm{n}$ & Positive Change & No Change & Negative Change \\
\hline Study abroad & 83 & $47(56 \%)$ & $9(11 \%)$ & $27(33 \%)$ \\
Global virtual team & 46 & $22(48 \%)$ & $9(20 \%)$ & $15(32 \%)$ \\
Combined total & 129 & $69(53 \%)$ & $18(14 \%)$ & $42(33 \%)$ \\
\hline
\end{tabular}

\section{Discussion, Insights, and Conclusions}

Affective personality characteristics like cultural dispositions can be difficult to measure and no instrument is every perfect. Still, we have learned much from analyzing these results. Dispositional attitudes towards culture seem to be distributed somewhat normally in the population; they vary individually by degree but are somewhat stable. Evidence also shows that instructional interventions and personal experience can alter cultural dispositions.

\subsection{Validation of the CDI}

The validation process for the CDI verified the existence of specific subcomponents that form an overall cultural disposition construct. Based on the results of the CFA used in the instrument validation process we were able to identify four clear components of cultural competence. The analysis suggests that participants tend to give similar answers to questions about appreciation, openness, and flexibility suggesting they might be very similar in nature. In fact, while developing questions for these subcomponents we found it difficult to identify subtle differences in these components of the cultural disposition construct. This result confirms Deardoff's (2011) 
assertion that, given the complexity of intercultural competence, a multimethod, multiperspective assessment plan is desirable.

\subsection{Hierarchical Relationship of Cultural Disposition Subcomponents}

We would expect that understanding, respecting, and being tolerant of cultural differences (i.e., crosscultural appreciation, openness, and flexibility) are important to one's ability to work on a culturally diverse team. What is less certain is whether having a desire to learn about other cultures, believing in cultural equality, or having a desire to solve cross-cultural global problems (i.e., global exploration, equality, and citizenship) might to the same some degree benefit an individual working on a culturally diverse team.

An analysis of these data suggests a hierarchical relationship within the subcomponents of cultural disposition. Participants consistently rated themselves highest on the appreciation/openness/flexibility aspects of cultural competence. They were more likely to indicate a willingness to explore other cultures than they were to believe in cross-cultural equality. They were least likely to indicate a positive attitude toward global citizenship. This pattern seems to align somewhat with Bloom's taxonomy for the affective domain (see Alshuler, Sussman, \& Kachur, 2003; Bloom, 1956).

Bloom (1956) described receiving and responding (i.e., listening and asking questions in order to fully understand) in ways that align best with cross-cultural appreciation and openness. The affective characteristic of valuing (i.e., being sensitive toward and respectful of individual and cultural differences) clearly aligns with crosscultural flexibility. Organizing values (i.e., accepting, prioritizing and resolving conflicting beliefs) seems to align best with cross-cultural exploration when individuals begin to extend their learning about cultural differences (understand, respect, and tolerate differences) to examine critical differences in terms of their value. The highest level in Blooms taxonomy for the affective domain is internalizing a value-complex (i.e., an adopted value system that dictates behavior). A belief regarding cultural equality or global citizenship may or may not result from crosscultural exploration. It would depend on the individuals involved and the way in which they organize the cultural values they examine. This may help explain why participants consistently seemed to rate the various aspects of cultural competence in a hierarchical fashion.

\subsection{Changes in Cultural Disposition}

While most of the participants in the pilot test seemed to have a positive experience interacting in culturally diverse settings or working on culturally diverse teams, not all had a positive educational experience. Supplemental 
data about these groups (i.e., interview results and descriptions of the experience) show that while the intent of a study abroad or GVT project is to give students a positive cultural experience, this does not always happen. About one third of the participants in the pilot study showed a decrease in CDI scores. Negative interaction with individuals from another culture would naturally have a negative effect on the individual's cultural disposition. Another plausible explanation for the decrease in cultural dispositions found in the responses of some students is that they simply reevaluated their previous overestimation of their attitude toward culture once they were exposed to a cultural setting that was new for them. Either way, clearly cultural dispositions are shaped and refined (positively or negatively) over time by cultural diversity experience.

\subsection{Use}

Both the study abroad and the GVT project are educational interventions designed to help students develop cultural competencies. Originally we anticipated that the CDI instrument might be used to determine the effectiveness of such instruction in accomplishing this goal. The results of this study suggest that the CDI is capable of such a determination. These findings and the validated instrument would be valuable to those wishing to measure any gains in cultural disposition students might have achieved as a resulted of any associated instructional interventions administer by educators to improve the cultural competence of their students. The use of such an instrument might have other beneficial implication for accreditation.

An analysis of the results from the pilot study suggests that both these educational interventions were somewhat successful. Cultural dispositions increased for most participants. It was also encouraging to see that the instrument was sensitive enough to identify those individuals whose attitudes toward culture changed negatively. Member checks in the form of interviews and observations verified that to some degree the educational experience (whether positive or negative) influenced an individual's attitudes toward culture. The repeated measure factorial ANOVA showed that both groups tended to have an increase in their cultural disposition from pretest to posttest as measured by the CDI. The amount and direction of change were similar for both groups of students. While more research is needed, this result suggests that a carefully planned GVT project can have beneficial outcomes similar to those of a study abroad experience in causing changes in students' cultural dispositions.

In addition to providing an aggregate analysis, clearly the CDI instrument shows promise in measuring any change in an individual student's cultural disposition. In this way the CDI might be use in helping individuals conduct a self-examination of their cultural attitudes. It would be unlikely that an individual score on the CDI 
would adequately predict whether an individual will be successful participating on a globally diverse team.

However, the CDI could be used to help students think about and more carefully reflect on their cultural dispositions. Reflection is an important part of developing intended affective characteristic like attitudes toward culture.

\subsection{Future Research}

While the validation process verified the existence of various aspects of cultural disposition, what we do not know from this analysis is which aspects of cultural disposition might affect an individual's ability to work effectively in a group. Additional research is also needed to explore which aspects of cultural disposition affect an individual's ability to work effectively in a culturally diverse group. In this regard a measure of cultural dispositions, like that of the CDI, would be needed along with a measure of the degree to which an individual successfully works on a culturally diverse team. In addition, it is possible that more work needs to be done to determine if an instrument like this is subject to differences in gender, race, or experience of those completing the assessment.

\section{Acknowledgment}

The authors gratefully acknowledge the National Science Foundation (grant EEC 0948997) for its financial support of this project. 


\section{References}

Altshuler, L., Sussman, N.M., \& Kachur, E. (2003). Assessing changes in intercultural sensitivity among physician trainees using the intercultural development inventory. International Journal of Intercultural Relations, 27, $387-401$.

Anderson, L.W., \& Bourke, S.F. (2000). Assessing affective characteristics in the schools. Mahwah, NJ: Lawrence Erlbaum Associates.

Ball A.G., Zaugg H., Davies R., Tateishi I., Parkinson A.R., Jensen C.G., and Maglegy S.P. (2011). Identification and validation of a set of global competencies for engineering students, International Journal of Engineering Education, 28(1), 156-168.

Barczak, G., McDonough, E., \& Athanassiou, N. (2006). So you want to be a global project leader? ResearchTechnology Management, 3449(3), 28-35. doi:10.1109/EMR.2006.261382

Bloom B.S. (1956). Taxonomy of educational objectives, Handbook I: The cognitive domain. New York, NY: David McKay Co Inc.

Brandl, J., \& Neyer, A. (2009). Applying cognitive adjustment theory to cross-cultural training for global virtual teams. Human Resource Management, 48(3), 341-353. doi: 10.1002/hrm.20284

Byrne, B.M. (2010). Structural equation modeling with AMOS: Basic concepts, applications, and programming (2nd ed.). New York, NY: Routledge.

Deardoff, D.K. (2011). Assessing Intercultural Competence, New Directions for Institutional Research, 2011(149), 65-79,

Duderstadt, J. J. (2008). Engineering for a changing world: A roadmap to the future of engineering practice, research, and education. Ann Arbor, MI: The University of Michigan.

Fantini, A.E. (2009). Assessing intercultural competence: Issues and Tools, In: Deardorff, D.K. (ed.), The SAGE Handbook of Intercultural Competence. Thousand Oaks, CA: Sage, 456-476.

Ferraro, G.P. (2006). The cultural dimensions of international business. Upper Saddle River, NY: Pearson Prentice Hall.

Grudzinski-Hall, M.G., Jellison, K.L.. Stewart-Gambino, H.W, and Weisman, R.N. (2007). Engineering Students in a Global World: Lehigh University’s Global Citizenship, Online Journal for Global Engineering Education, 2, np.

Hunter W. D., White, G. P. and Godbey, G. C. (2006). What does it mean to be globally competent? Journal of Studies in International Education, 10, 267-285.

Ingram, S. \& Friesen, M. (2013). Advancing Intercultural Competency: Canadian engineering employers' experiences with immigrant engineers. European Journal of Engineering Education. 38(2), p. 219-227. doi: 10.1080

Jansen, D. E., \& Pudlowski, Z. J. (2009) Global engineers: Creating needed solutions through intercultural competence. International Journal of Engineering Education, 25, 1292-1297. 
Jesiek, B.K., Borrego, M. B., \& Beddoes, K. (2010). Advancing global capacity for engineering education research (AGCEER): Relating research to practice, policy and industry. Journal of Engineering Education, 99(2), $107-119$.

Koester, J., and Olebe, M. (1988). The behavioral assessment scale for intercultural communication effectiveness. International Journal of Intercultural Relations, 12, 233-246.

Krathwohl, D. R., Bloom, B. S., \& Masia, B. B. (1973). Taxonomy of educational objectives, the classification of educational goals. Handbook II: Affective domain. New York, NY: David McKay Co., Inc.

Lohmann, J. R., Rollins, H. A., \& Hoey, J. J., (2006). Defining, developing and assessing global competence in engineers. European Journal of Engineering Education. 31, 119-131.

McNair, L., Paretti, M. C., \& Kakar, A. (2008). Case study of prior knowledge: Expectations and identity constructions in interdisciplinary, cross-cultural virtual collaboration. International Journal of Engineering Education, 24(2), 386-399.

Miller, M. D., Linn, R. L., and Gronlund, N. E. (2009). Measurement and assessment in teaching. Upper Saddle River, NJ: Pearson Education Ltd.

Neuliep, J. W., \& McCroskey, J. C. (1997). The development of a U.S. and generalized ethnocentirism scale. Communication Research Reports, 14(4), 385-395.

Olson, C. L., and Kroeger, K. R. (2001). Global competency and intercultural sensitivity. Journal of Studies in International Education, 5(2), 116-137.

Parkinson, A., (2009). The rationale for developing global competence. Online Journal for Global Engineering Education. 4, 2.

Prasad, K., \& Akhilesh, K. B. (2002). Global virtual teams: What impacts their design and performance? Team Performance Management: An International Journal, 8, 102-112. doi: 10.1108/13527590210442212

Rasmussen, L.B., \& Wangel, A. (2006). Work in the virtual enterprise — creating identities, building trust, and sharing knowledge. AI \& Society, 21(1-2), 184-199. doi:10.1007/s00146-005-0029-y

Ruben, B.D., \& Kealey, D. (1979). Behavioral assessment of communication competency and the prediction of cross-cultural adaptation. International Journal of Intercultural Relations, 3, 15-48.

Sinicrope, C., Norris, J., \& Watanabe, Y. (2007). Understanding and assessing intercultural competence: A summary of theory, research, and practice. Second Language Studies, 26(1), 1-58.

Spitberg B. H. and Changnon, G. (2009). Conceptualizing Intercultural Competence, In: Deardorff, D. K. (ed.), The SAGE Handbook of Intercultural Competence. Thousand Oaks, CA: Sage, pp. 2-52.

Wojciechowski, J., \& Standridge, C. (2010). The mutual re-enforcement of curricular education and co-operative education: A case study. Proceedings of the American Society for Engineering Education Annual Conference, 1-9. 